\title{
言 \\ Normalised rotation capacity for deformability evaluation of high-performance concrete beams
}

\author{
K.J.H. Zhou, J.C.M. Ho* and R.K.L. Su \\ Department of Civil Engineering, The University of Hong Kong, Hong Kong \\ (Received April 7, 2010, Accepted July 22, 2010)
}

\begin{abstract}
High-strength concrete (HSC) is becoming more popular in the construction of beams and columns of tall buildings because of its higher stiffness and strength-to-weight ratio. However, as HSC is more brittle than normal-strength concrete (NSC), it may adversely affect the flexural ductility and deformability of concrete members. Extended from a series of theoretical study conducted on flexural ductility of concrete beams, the authors would in this paper investigate the effects of some critical factors including the degree of reinforcement, confining pressure, concrete and steel yield strength on the flexural deformability of NSC and HSC beams. The deformability, expressed herein in terms of normalised rotation capacity defined as the product of ultimate curvature and effective depth, is investigated by a parametric study using nonlinear moment-curvature analysis. From the results, it is evident that the deformability of concrete beams increases as the degree of reinforcement decreases and/or confining pressure increases. However, the effects of concrete and steel yield strength are more complicated and dependent on other factors. Quantitative analysis of all these effects on deformability of beams has been carried out and formulas for direct deformability evaluation are developed. Lastly, the proposed formulas are compared with available test results to verify its applicability.
\end{abstract}

Keywords: beams; curvature; deformability; high-strength concrete; reinforced concrete; rotation capacity.

\section{Introduction}

In recent years, there has been rapid development of high-performance materials such as highstrength concrete (HSC) and high-strength steel (HSS). With the advent of superplasticiser and superfine materials such as microsilica, pulverised fuel ash and slag, the compressive strength of HSC was significantly improved. Compared with the classical normal-strength concrete (NSC), HSC is characterised not only by its higher strengths (compressive, tensile and shear) and stiffness (Carrasquillo et al. 1981), but also by its reduced permeability due to better packing density that improves the durability of the concrete structures. Because of its improved strengths, HSC is increasingly adopted in various structural members in tall buildings so as to reduce the member size and save space. Furthermore, because of the enhanced resistance, HSC is often selected as the construction material for water-retaining and maritime structures.

Apart from HSC, HSS with yield strength higher than $500 \mathrm{MPa}$ is also increasingly adopted as longitudinal and confining reinforcement in concrete members (Restrepo et al. 2006). One of the

\footnotetext{
* Corresponding author, Assistant Professor, E-mail: johnny.ho@hku.hk
} 
advantages of adopting HSS is that it provides the same strength with a smaller steel area, which relieves the steel congestion problem at lap splice locations and within beam-column joints. When HSS is adopted as confining reinforcement within the critical regions of beams and columns, it allows a larger spacing of confinement for a given confining pressure. Not only it helps improve the concrete placing quality within the critical region of beams and columns, but also mitigates spalling of the concrete covers.

Despite the above advantages, HSC and HSS are more brittle than NSC and normal-strength steel (NSS) respectively. Also, HSS may fracture when the concrete section is excessively underreinforced (Ho et al. 2005, Bai and Au 2009). At high working stress, HSS may also buckle prematurely. When HSS is used as confinement, the yield strength may not be fully developed and hence reduce the effectiveness in confining the concrete core. Obviously, structures constructed of HSC and/or HSS should be designed with careful reinforcement detailing such that plastic hinge can be fully developed and moment redistribution can occur during extreme events such as earthquake attack, shock and blasting (Lu 2009, Nam et al. 2009, Weerheijm et al. 2009). This would avoid the structural members to fail abruptly in a brittle manner when their maximum deformability has been reached (Wu et al. 2004, Lam et al. 2008, Teran-gilmore et al. 2010).

To ensure that plastic hinge can be developed in HSC concrete beams with/without HSS, it is essential to provide the beam with adequate flexural ductility by careful reinforcement design and detailing (Bindhu et al. 2008, Belarbi et al. 2009, Pam and Ho 2010). In a series of theoretical study based on nonlinear moment-curvature analysis taking into account the stress-path dependence of steel reinforcement (Pam et al. 2001, Ho et al. 2003, Lam et al. 2009, Ho et al. 2010a), the authors have investigated various factors that would affect the flexural ductility of concrete beams and columns. The nonlinear moment-curvature analysis is stress-path dependence because it takes into account the reduction in tensile stress of tension steel after yielding when the beam section softens. At this stage, the moment capacity of the beam sections starts to drop and the neutral axis depth increases rapidly. This reduces the strain in tension steel and thereby causing strain reversal in tension steel that decreases its tensile stress. In those studies, the investigated parameters include the degree of reinforcement, concrete strength, steel yield strength and amount of confining reinforcement. The degree of reinforcement measures the degree of beam section being under- or over-reinforced. A more complete definition will be given in Eq. (4).

In general, the flexural ductility increases as the degree of reinforcement and/or tension steel yield strength decreases. However, the effects of concrete strength on ductility are fairly complicated and are dependent on other factors. At a fixed tension and/or compression steel ratio, which is defined as the tension and/or compression steel area divided by the effective area of beam section (i.e. breadth $\times$ effective depth), using HSC will increase ductility of concrete beams. Nonetheless, at a fixed degree of reinforcement, using HSC will decrease the ductility. On the other hand, increasing the confining pressure provided by various types of confinement in forms of closely-spaced transverse reinforcement (Ho and Pam 2003, Bechtoula et al. 2009, Pam and Ho 2009), external steel plates (Altin et al. 2008, Su et al. 2009, Zhu and Su 2010) or high-strength fibre plates (Ramadoss and Nagamani 2009, Sadjadi and Kianoush 2010), concrete-filled steel tube (Cho et al. 2008, Feng and Young 2009), steel-concrete composite section (Park and Kim 2008), FRP wraps (Lee et al. 2008, Hashemi et al. 2008, Mahini and Ronagh 2009) and other methods (Wu 2008) would always increase the ductility of concrete beams.

Whilst it is important to design structures with a nominal level of flexural ductility, it is also necessary to provide the structures with adequate flexural deformability in terms of ultimate rotation 
capacity from the performance-based design point of view (Englekirk 2008, Park et al. 2008, Goel 2010). This is because the flexural ductility is an indication of deformability at ultimate state of beams relative to the deformability at first yield (Watson and Park 1994). In concrete structures constructed of HSC and/or HSS where the yield deformation is relatively small due to larger initial elastic stiffness, the ductility may not be a good indicator of its ultimate deformability in absolute magnitude. With the provision of adequate deformability at ultimate state, the structures are able to cater for large inelastic deformability demand imposed by earthquake without causing collapse.

In reinforced concrete beams, the deformability could be assessed by their ultimate rotation capacity. Up to now, the method provided in Eurocode 2 (ECS 2004) for beam design for a prescribed rotation demand is too simplified and conservative (Hawileh et al. 2009, Ho et al. 2010b), which is independent on steel yield strength and confining reinforcement content. Thus, the current design method may not provide adequate deformability to beams made of HSS and/or HSC. A detailed study on the factors affecting the deformability of concrete beams should therefore be carried out and a new method be established to allow rapid deformability design for concrete beams.

In this paper, the deformability of concrete beams with various concrete strength, steels (tension and compression) yield strength and confining pressure are assessed by nonlinear moment-curvature analysis taking into account the stress-path dependence of the constitutive materials (Pam et al. 2001). The deformability of concrete beams is studied herein by normalised rotation capacity, which is the product of the ultimate curvature and effective depth. The normalised rotation capacity gives the ultimate rotation of concrete beams with plastic hinge length equal to its effective depth. For beams with other plastic hinge length, the ultimate rotation could be obtained by multiplying the normalised rotation capacity with the ratio of plastic hinge length to effective depth. Based on this definition, deformability analyses of different beam sections containing concrete strength from 40 to $100 \mathrm{MPa}$, steel yield strength of 400 to $800 \mathrm{MPa}$ and confining pressure from 0 to $4 \mathrm{MPa}$ were carried out through a series of parametric studies. From the results, two formulas are proposed for direct evaluation of the deformability of concrete beams in terms of normalised rotation capacity. Lastly, the proposed formulas are compared with available test results obtained by other researchers for verification.

\section{Nonlinear moment-curvature analysis}

The method of nonlinear moment-curvature analysis developed previously by the authors (Pam et al. 2001, Ho et al. 2003) has been adopted in this study for the deformability analysis of concrete beams. It takes into account the constitutive stress-strain curve of concrete and steel as well as the stress-path dependence of the steel reinforcement. The concrete stress-strain curves proposed by Attard and Setunge (1996) are adopted. For steel reinforcement, the idealised linearly elastic perfectly plastic stress-strain curve is adopted. The stress-strain curves of concrete and steel reinforcement are shown in Fig. 1.

Five basic assumptions are made in the analysis: (1) Plane sections before bending remain plane after bending. (2) The tensile strength of the concrete may be neglected. (3) There is no relative slip between concrete and steel reinforcement. (4) The concrete core is confined while the concrete cover is unconfined. (5) The confining pressure provided to the concrete core by confinement is assumed to be constant throughout the concrete compression zone. Assumptions (1) to (4) are 


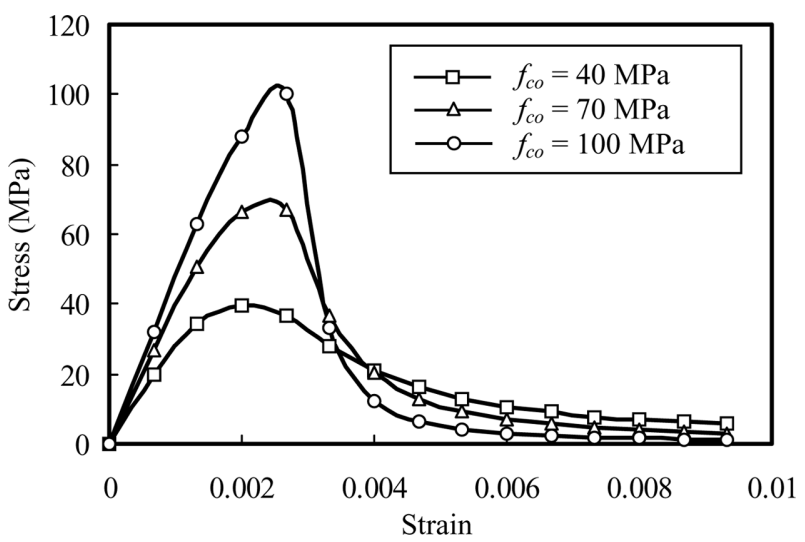

(a)

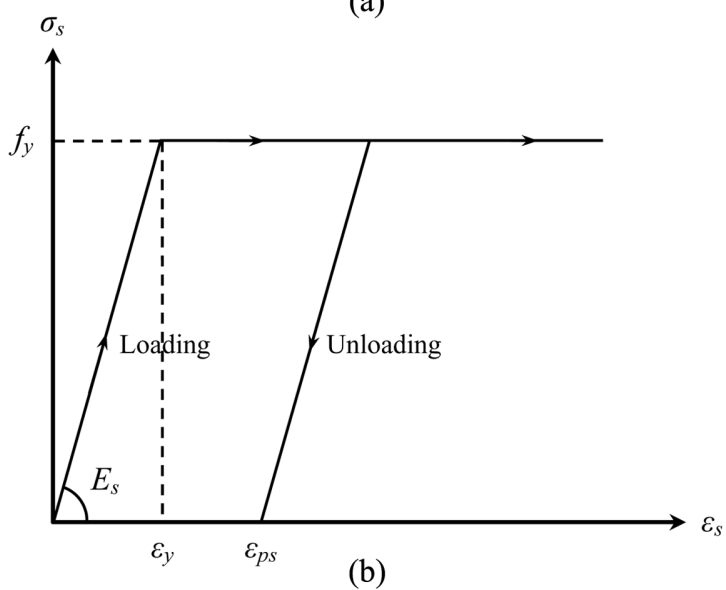

Fig. 1 Stress-strain curves of concrete and steel reinforcement: (a) Stress-strain curves of concrete, (b) Stressstrain curve of steel with stress-path dependence considered

commonly accepted and have been adopted by various researchers (Pam and Ho 2001, Ho et al. 2004, Bai et al. 2007, Au et al. 2009, Kwak and Kim 2010). Assumption (5) is not exact because the confining pressure varies in the concrete compression zone with strain gradient. However, it is a fairly reasonable assumption (Ho et al. 2010a) because: (i) At small concrete strains, the variation of confining pressure would not have significant effect on the confined concrete stress. (ii) When strain of the extreme fibre of confined concrete reaches about 0.003-0.004 before concrete cover spalls off entirely, there would be some variations of confining pressure within the concrete compression zone due to strain gradient. However, as this happens within a narrow range of concrete strain, the differences in the confined concrete compressive force and moment capacity of column are not significant. (iii) After the concrete cover had spalled off completely at large concrete strain, the Poisson's ratio of concrete increases abruptly that causes the confining steel to yield. The confining pressure becomes a constant, which only depends on the volumetric ratio and yield strength of confining steel. In the analysis, the moment-curvature behaviour of the beam section is analysed by applying prescribed curvatures incrementally starting from zero. At a prescribed curvature, the stresses developed in the concrete and the steel are determined from the strain profile across the section and their respective stress-strain curves. Then, the neutral axis depth and resisting 
moment are evaluated from the axial force and moment equilibrium conditions, respectively. The above procedure is repeated until the curvature is large enough for the resisting moment to increase to the peak and then decrease to $80 \%$ of the peak moment.

\section{Flexural deformability analyses}

\subsection{Flexural deformability analysis}

The flexural deformability of beam sections are expressed in terms of normalised rotation capacity $\theta_{p l}$ defined as follows

$$
\theta_{p l}=\phi_{\imath} d
$$

where $\phi_{u}$ is the ultimate curvature, $d$ is the effective depth of the beam section. The ultimate curvature $\phi_{u}$ is taken as the curvature when the resisting moment has dropped to $0.8 M_{p}$ after reaching $M_{p}$, where $M_{p}$ is the peak moment. The value of $\theta_{p l}$ evaluated from Eq. (1) would give the rotation capacity of the beam with plastic hinge length equal to its effective depth. However, since the plastic hinge length depends on the loading condition, concrete strength, steel content and confining pressure, the actual rotation capacity of concrete beams should be obtained by multiplying $\theta_{p l}$ with $l_{p} / d$, where $l_{p}$ is the actual plastic hinge length (Mendis 2001).

Based on the above definition, a comprehensive parametric study on the effects of various factors on the normalised rotation capacity has been conducted. The studied factors are: (1) Degree of reinforcement; (2) Concrete strength; (3) Steel yield strength; and (4) Confining pressure. The beam sections analysed in the parametric study are shown in Fig. 2. The concrete strength $f_{c o}$ was varied from 40 to $100 \mathrm{MPa}$, the confining pressure $f_{r}$ was varied from 0 to $4 \mathrm{MPa}$, the tension steel ratio $\rho_{t}$

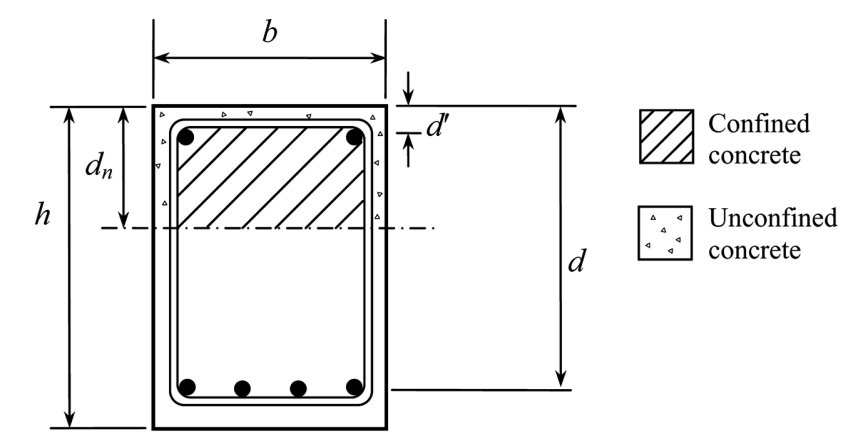

$\underline{\text { Section properties }}$

- $b=300 \mathrm{~mm}$

- $h=600 \mathrm{~mm}$

- $d^{\prime \prime}=50 \mathrm{~mm}$

- $d=550 \mathrm{~mm}$
- $f_{c o}=40$ to $100 \mathrm{MPa}$

- $f_{y}=400$ to $800 \mathrm{MPa}$

- $f_{r}=0$ to $4 \mathrm{MPa}$

- $\rho_{t}=A_{s t} / b d=0.4$ to $2 \rho_{b}$

- $\rho_{c}=A_{s c} b d=0$ to $2 \%$

Fig. 2 Beam sections analysed 
was varied from 0.4 to 2 times the balanced steel ratio, the compression steel ratio $\rho_{c}$ was varied from 0 to $2 \%$, and the steel (compression and tension) yield strength $f_{y}$ was varied from 400 to 800 MPa.

\subsection{Failure modes and balanced steel ratio}

It was observed from previous theoretical studies (Pam et al. 2001, Ho et al. 2003) that the ultimate curvature of concrete beams is determined by the failure mode. In total three failure modes were observed: (1) Tension failure - tension steel yields during failure; (2) Compression failure none of tension steel yields during failure; and (3) Balanced failure - the most highly stressed tension steel has just yielded during failure. The tension steel ratio of a singly-reinforced beam section having balanced failure is defined as the balanced steel ratio denoted by $\rho_{b o}=A_{s b} / b d$, where $A_{s b}$ is the balanced steel area. For beam sections with non-zero compression steel ratio $\rho_{c}$ and unequal tension $f_{y t}$ and compression $f_{y c}$ steel yield strengths, $\rho_{b}$ can be expressed as

$$
\rho_{b}=\rho_{b o}+\left(f_{y c} / f_{y t}\right) \rho_{c}
$$

The values of $\rho_{b o}$ for various concrete strengths and confining pressure have been evaluated using nonlinear moment-curvature analysis and are listed in Tables 1,2 and 3 for $f_{y t}=400,600$ and $800 \mathrm{MPa}$ respectively. For simplicity of design application, the following empirical equation was derived by

Table 1 Balanced steel ratios $\rho_{b o}$ for tension steel yield strength $f_{y t}=400 \mathrm{MPa}$

\begin{tabular}{cccccc}
\hline \hline \multirow{2}{*}{$f_{c o}(\mathrm{MPa})$} & \multicolumn{5}{c}{ Balanced steel ratios without compression reinforcement $\rho_{b o}(\%)$} \\
\cline { 2 - 6 } & $f_{r}=0 \mathrm{MPa}$ & $f_{r}=1 \mathrm{MPa}$ & $f_{r}=2 \mathrm{MPa}$ & $f_{r}=3 \mathrm{MPa}$ & $f_{r}=4 \mathrm{MPa}$ \\
\hline 40 & 4.74 & 5.98 & 6.90 & 7.73 & 8.56 \\
50 & 5.63 & 6.91 & 7.86 & 8.78 & 9.60 \\
60 & 6.46 & 7.79 & 8.77 & 9.70 & 10.59 \\
70 & 7.29 & 8.62 & 9.61 & 10.54 & 11.50 \\
80 & 8.06 & 9.38 & 10.37 & 11.35 & 12.29 \\
90 & 8.77 & 10.11 & 11.13 & 12.11 & 13.03 \\
100 & 9.42 & 10.80 & 11.82 & 12.78 & 13.76 \\
\hline
\end{tabular}

Table 2 Balanced steel ratios $\rho_{b o}$ for tension steel yield strength $f_{y t}=600 \mathrm{MPa}$

\begin{tabular}{cccccc}
\hline \hline \multirow{2}{*}{$f_{c o}(\mathrm{MPa})$} & \multicolumn{5}{c}{ Balanced steel ratios without compression reinforcement $\rho_{b o}(\%)$} \\
\cline { 2 - 6 } & $f_{r}=0 \mathrm{MPa}$ & $f_{r}=1 \mathrm{MPa}$ & $f_{r}=2 \mathrm{MPa}$ & $f_{r}=3 \mathrm{MPa}$ & $f_{r}=4 \mathrm{MPa}$ \\
\hline 40 & 2.74 & 3.60 & 4.23 & 4.83 & 5.37 \\
50 & 3.23 & 4.12 & 4.78 & 5.40 & 6.00 \\
60 & 3.69 & 4.61 & 5.29 & 5.93 & 6.55 \\
70 & 4.13 & 5.06 & 5.76 & 6.41 & 7.04 \\
80 & 4.56 & 5.50 & 6.19 & 6.85 & 7.49 \\
90 & 4.94 & 5.90 & 6.59 & 7.28 & 7.91 \\
100 & 5.29 & 6.27 & 6.97 & 7.67 & 8.29 \\
\hline
\end{tabular}


Table 3 Balanced steel ratios $\rho_{b o}$ for tension steel yield strength $f_{y t}=800 \mathrm{MPa}$

\begin{tabular}{cccccc}
\hline \hline \multirow{2}{*}{$f_{c o}(\mathrm{MPa})$} & \multicolumn{5}{c}{ Balanced steel ratios without compression reinforcement $\rho_{b o}(\%)$} \\
\cline { 2 - 5 } & $f_{r}=0 \mathrm{MPa}$ & $f_{r}=1 \mathrm{MPa}$ & $f_{r}=2 \mathrm{MPa}$ & $f_{r}=3 \mathrm{MPa}$ & $f_{r}=4 \mathrm{MPa}$ \\
\hline 40 & 1.82 & 2.48 & 2.96 & 3.42 & 3.84 \\
50 & 2.13 & 2.82 & 3.33 & 3.80 & 4.25 \\
60 & 2.43 & 3.14 & 3.66 & 4.14 & 4.61 \\
70 & 2.70 & 3.43 & 3.96 & 4.45 & 4.93 \\
80 & 2.97 & 3.69 & 4.22 & 4.75 & 5.21 \\
90 & 3.22 & 3.95 & 4.50 & 5.00 & 5.49 \\
100 & 3.44 & 4.19 & 4.74 & 5.22 & 5.74 \\
\hline
\end{tabular}

regression analysis based on the data obtained in the above tables

$$
\rho_{b o}=0.005\left(f_{c o}\right)^{0.58}\left(1+1.2 f_{r}\right)^{0.3}\left(f_{y t} / 460\right)^{-1.35}
$$

It should be noted that all strengths are in $\mathrm{MPa}$ and $400 \mathrm{MPa} \leq f_{y t} \leq 800 \mathrm{MPa}$.

\section{Flexural deformability of high-strength concrete beams}

\subsection{Effect of degree of reinforcement}

From a series of previous theoretical studies carried out by the authors on the flexural ductility of HSC beams (Pam et al. 2001, Ho et al. 2003), it was found that the most critical factor that determines the ductility of HSC beams is the degree of reinforcement $\lambda$ defined as follows

$$
\lambda=\frac{f_{y t} \rho_{t}-f_{y c} \rho_{c}}{f_{y t} \rho_{b o}}
$$

The beam section is classified as under-reinforced, balanced and over-reinforced sections when $\lambda$ is less than, equal to and larger than 1.0 respectively.

To study the effects of the degree of reinforcement $\lambda$ on the flexural deformability of HSC beams, the normalised rotation capacity $\theta_{p l}$ obtained from the parametric study is plotted against $\lambda$ for different concrete strengths of $f_{c o}=40,70$ and $100 \mathrm{MPa}$ in Fig. 3(a). From the figure, it is obvious that the deformability of concrete beams decreases as $\lambda$ increases for all concrete strengths until $\lambda$ reaches 1.0. After that, the deformability remains relatively constant. It is also observed that at a fixed $\lambda$, the deformability decreases as the concrete strength increases. Therefore, the use of HSC at a fixed degree of reinforcement would reduce the deformability of concrete beams.

\subsection{Effects of concrete strength}

To study the effects of concrete strength $f_{c o}$ on the deformability of concrete beams, the normalised rotation capacity $\theta_{p l}$ is plotted against the tension steel ratio $\rho_{t}$ in Fig. 3(b) for $f_{c o}=40$, 


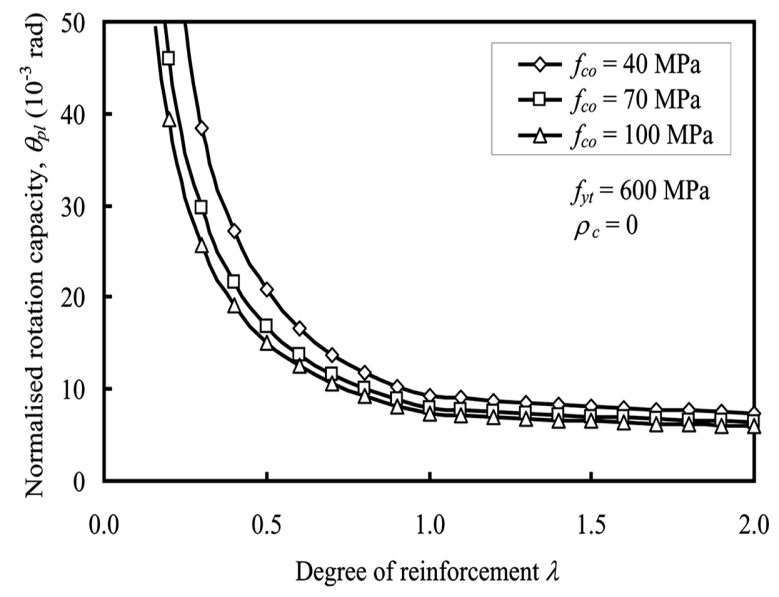

(a)

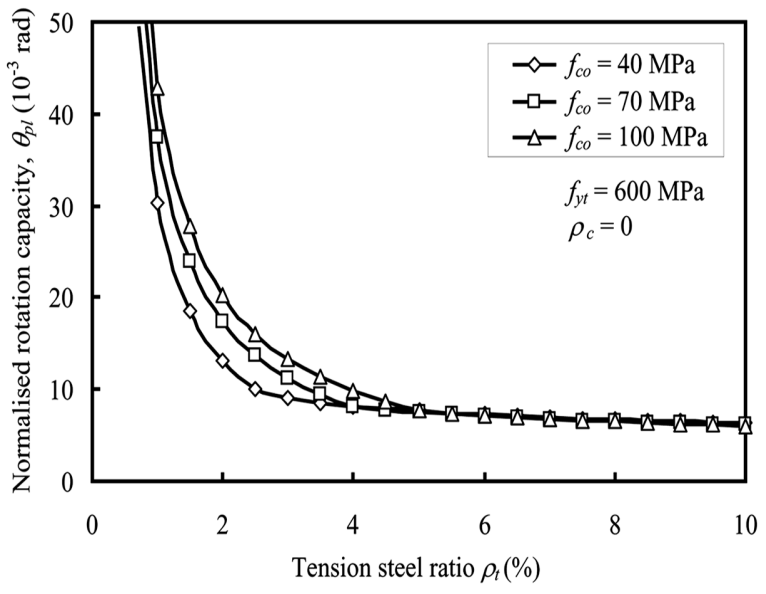

(b)

Fig. 3 Effects of concrete strength on flexural deformability of beams: (a) $\theta_{p l}$ against $\lambda$, (b) $\theta_{p l}$ against $\rho_{t}$

70 and $100 \mathrm{MPa}$. From Fig. 3(b), it is seen that the deformability decreases as the tension steel ratio increases at all concrete strengths until $\rho_{t}=\rho_{b o}$. However, unlike the variation with $\lambda$ as shown in Fig. 3(a), the deformability increases as the concrete strength increases at a given $\rho_{t}$, albeit that HSC is more brittle per se. This is because as concrete strength increases, the balanced steel ratio $\rho_{b o}$ also increases (see Eq. 3). Thus, at a given tension steel ratio, the degree of reinforcement decreases that leads to a larger deformability. Therefore, the use of HSC could improve the deformability at a given tension steel ratio. Meanwhile, higher strength concrete would offer a larger flexural strength at a given tension steel ratio. Therefore, the advantage of using HSC in lieu of NSC in concrete beams is that it can improve the flexural behaviour of beams in terms of both flexural strength and deformability simultaneously.

\subsection{Effects of steel area and yield strength}

To study the effects of yield strength of tension steel $f_{y t}$ on the deformability of concrete beams, the normalised rotation capacity $\theta_{p l}$ obtained in the parametric study is plotted against $\lambda$ in Fig. 4(a) and $\rho_{t}$ in Fig. 4(b) for different values of $f_{y t}=400,600$ and $800 \mathrm{MPa}$ for beam sections with $f_{c o}=$ $70 \mathrm{MPa}$. From Fig. 4(a), it is evident that the deformability of beam increases as the tension steel yield strength increases at the same degree of reinforcement until it reaches 1.0, after which the normalised rotation capacities converges. On the other hand, it is observed from Fig. 4(b) that the deformability decreases significantly at a fixed $\rho_{t}$ as the tension steel yield strength increases until $\rho_{t}$ reaches about $6 \%$. This is because the balanced steel ratio $\rho_{b o}$ decreases rapidly or $f_{y t}$ increases (see Eq. 3). Therefore, at the same tension steel ratio, the degree of reinforcement to a lower deformability. Nevertheless, for the same flexural strength requirement, the use of HSS as tension steel will allow a smaller steel area. Hence, the deformability of concrete beam may or may not be significantly affected.

Figs. 5(a) and 5(b) show the effects of compression steel yield strength $f_{y c}=400,600$ and 800 $\mathrm{MPa}$ on the deformability of concrete beams at various degrees of reinforcement $\lambda$ and tension steel ratio $\rho_{t}$ respectively for $f_{c o}=70 \mathrm{MPa}$ and $\rho_{c}=1 \%$. From both figures, it can be seen that the use of 


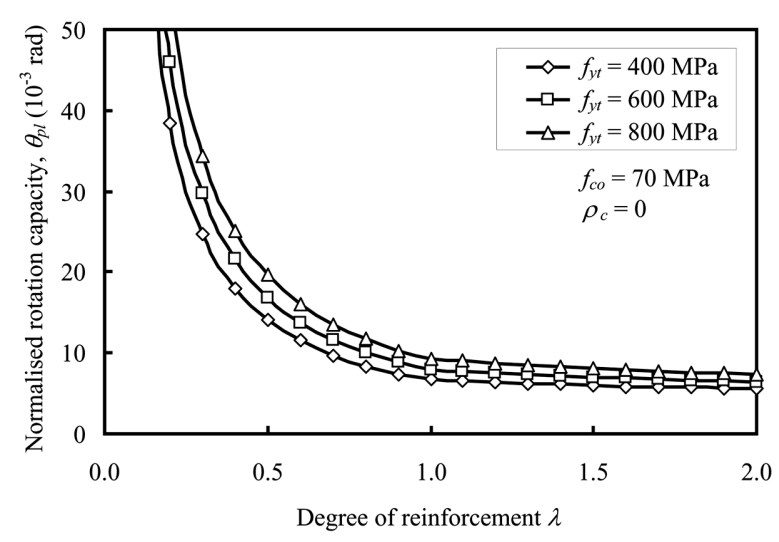

(a)

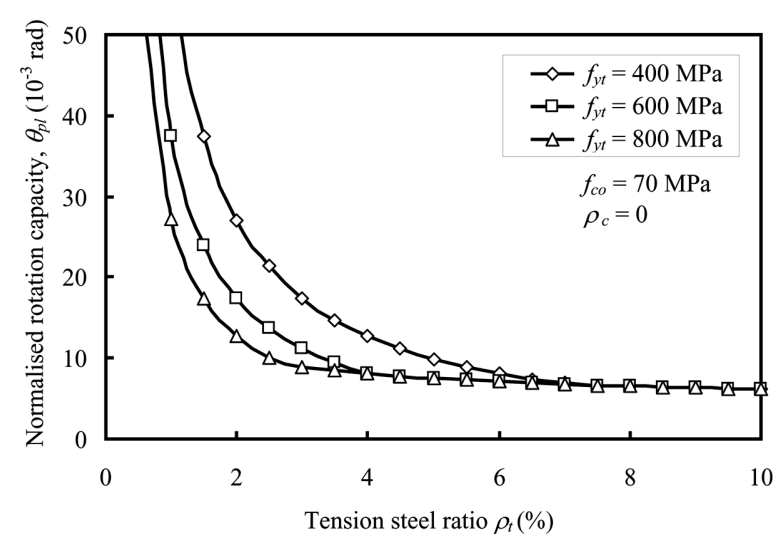

(b)

Fig. 4 Effects of tension steel yield strength on flexural deformability of beams: (a) $\theta_{p l}$ against $\lambda$, (b) $\theta_{p l}$ against $\rho_{t}$

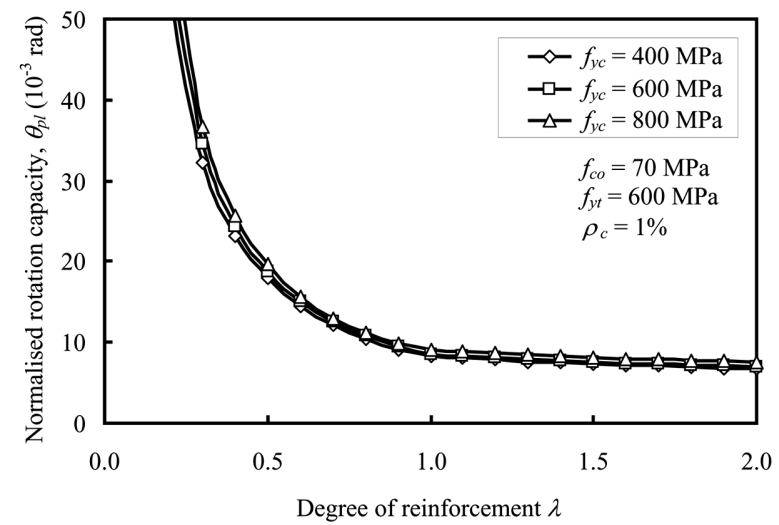

(a)

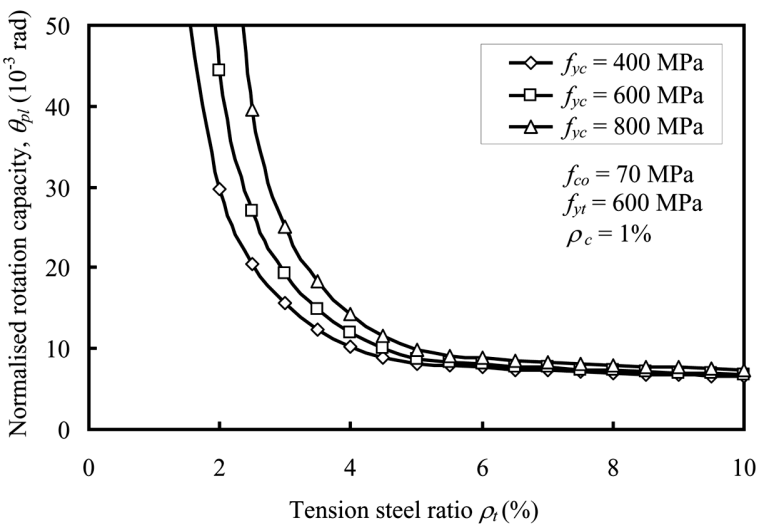

(b)

Fig. 5 Effects of compression steel yield strength on flexural deformability of beams: (a) $\theta_{p l}$ against $\lambda$, (b) $\theta_{p l}$ against $\rho_{t}$

HSS as compression steel would improve the deformability of beam slightly at a given $\lambda$, but it improves the deformability of beams significantly at a given $\rho_{t}$. This is because at constant tension and compression steel ratios, the increase in compression steel yield strength would reduce the value of $\lambda$ (see Eq. 4) and hence increase the deformability.

\subsection{Effects of confining pressure}

To study the effect of the confining pressure $f_{r}$, the normalised rotation capacity $\theta_{p l}$ obtained in the parametric study is plotted against confining pressures $f_{r}$ for different concrete strength $f_{c o}=40,70$ and $100 \mathrm{MPa}$ in Fig. 6(a), degree of reinforcement $\lambda=0.5,1.0$ and 1.5 in Fig. 6(b) and tension steel ratios $\rho_{t}=2,4$ and $6 \%$ in Fig. 6(c). It is evident from Fig. 6(a) that at a given $\lambda$, the normalised rotation capacity $\theta_{p l}$ increases as the confining pressure $f_{r}$ increases for all concrete strength. It is also evident from Fig. 6(b) that at a fixed $f_{c o}, \theta_{p l}$ increases as $f_{r}$ increases for all $\lambda$. These are because of the gradual increase in material ductility and deformability of the confined 


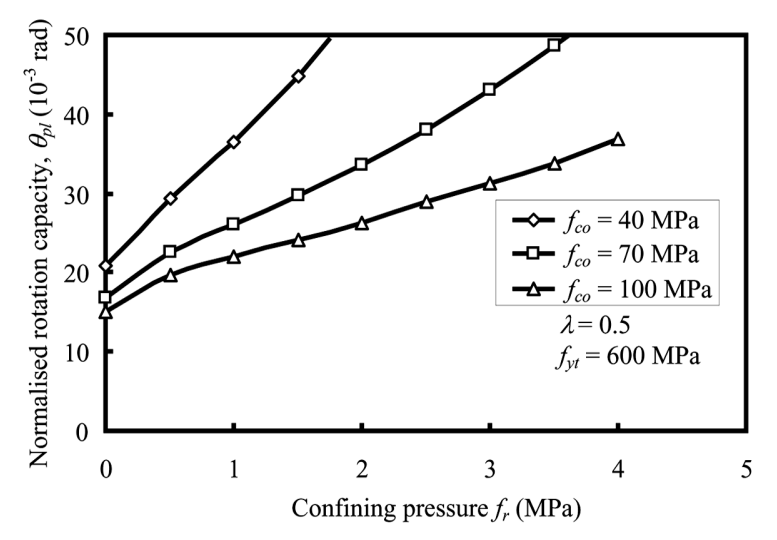

(a)

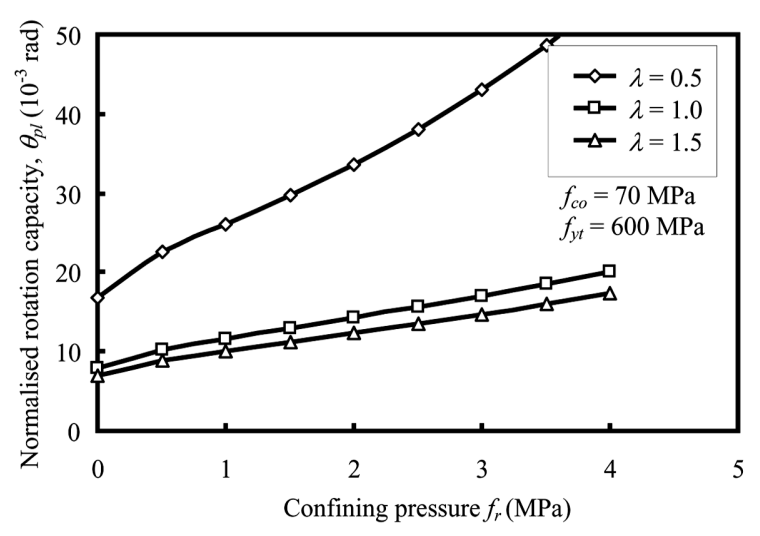

(b)

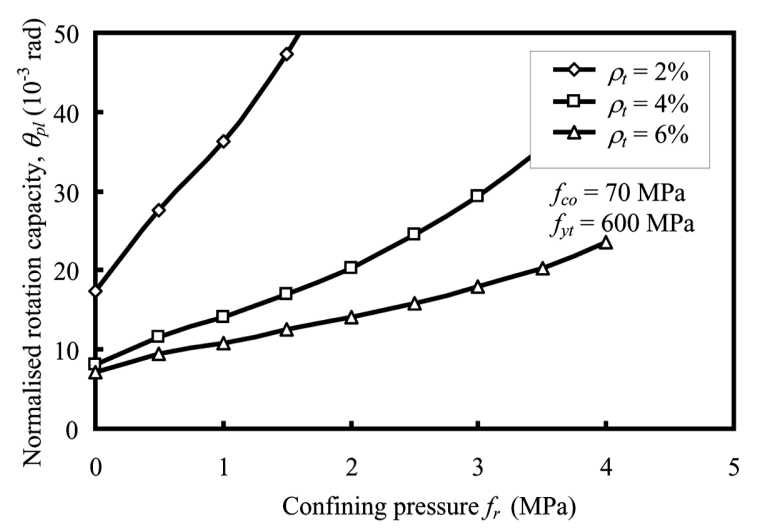

(c)

Fig. 6 Effects of confining pressure on flexural deformability of beams: (a) $\theta_{p l}$ against $f_{r}$ for different $f_{c o}$, (b) $\theta_{p l}$ against $f_{r}$ for different $\lambda$, (c) $\theta_{p l}$ against $f_{r}$ for different $\rho_{t}$

concrete as the confining pressure $f_{r}$ increases at a given $\lambda$. In Fig. $6(\mathrm{c})$, it is seen that at a fixed $f_{c o}$, $\theta_{p l}$ increases as the confining pressure $f_{r}$ increases for all $\rho_{t}$. This is because apart from the enhanced material ductility and deformability of the confined concrete, the balanced steel ratio $\rho_{b o}$ also increases with the confining pressure $f_{r}$ (Kwan et al. 2004), which decreases the degree of reinforcement $\lambda$ and further increases the normalised rotation capacity $\theta_{p l}$.

Nevertheless, it is also evident from the above figures that the effectiveness of adding confinement to improve the deformability of concrete beams decreases as the degree of reinforcement $\lambda$ and/or concrete strength $f_{c o}$ increases. For example, it is seen in Fig. 6(a) that the provision of $f_{r}=1 \mathrm{MPa}$ could improve the deformability from 0.021 to $0.036 \mathrm{rad}$ (an increase of $75 \%$ ) for beam section with $f_{c o}=40 \mathrm{MPa}$. However, the same provision of $f_{r}$ could only improve the deformability from 0.017 to $0.026 \mathrm{rad}$ (an increase of $54 \%$ ) for beam section with $f_{c o}=70 \mathrm{MPa}$ and from 0.015 to $0.021 \mathrm{rad}$ (an increase of $40 \%$ ) for beam section with $f_{c o}=100 \mathrm{MPa}$. Similar phenomenon of reduction in deformability improvement with the degree of reinforcement is also observed in Fig. 6(b). Therefore, the deformability improvement due to provision of confinement is dependent on the concrete strength and degree of reinforcement. The effectiveness of providing confining pressure to improve the deformability of beams may be studied in terms of the differential 


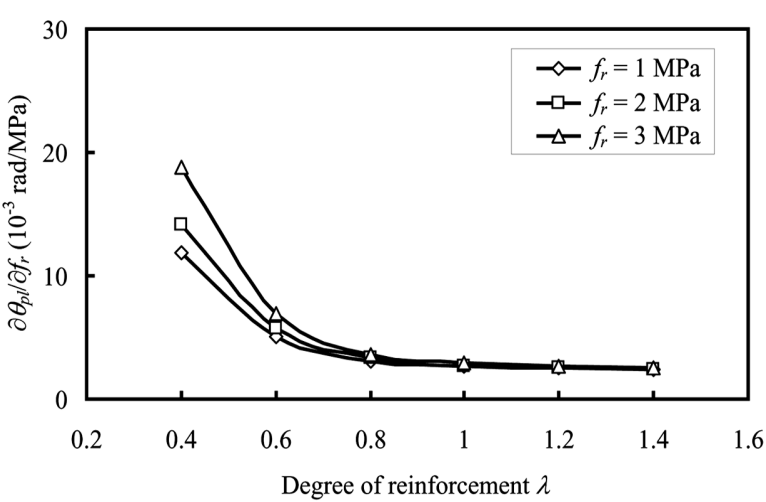

(a)

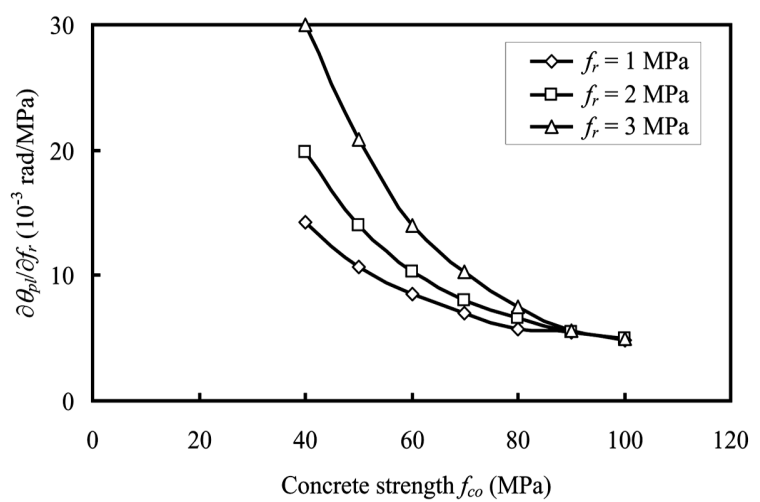

(b)

Fig. 7 Effects of $\lambda$ and $f_{c o}$ on effectiveness of confinement: (a) $\partial \theta_{p l} / \partial f_{r}$ against $\lambda$, (b) $\partial \theta_{p l} / \partial f_{r}$ against $f_{c o}$

coefficient of $\theta_{p l}$ with respect to $f_{r}$, denoted herein by $\partial \theta_{p l} / \partial f_{r}$. To study how the concrete strength and degree of reinforcement affect the effectiveness of confinement on deformability improvement, the differential coefficient $\partial \theta_{p l} / \partial f_{r}$ is plotted against $\lambda$ and $f_{c o}$ in Figs. 7(a) and 7(b) respectively.

From Fig. 7(a), it can be seen that the differential coefficient $\partial \theta_{p l} / \partial f_{r}$ decreases as the degree of reinforcement $\lambda$ increases until it reaches a steady value at $\lambda \geq 0.8$. This indicates that the increase in deformability of concrete beam per unit increase in confining pressure is always smaller at a higher degree of reinforcement. Therefore, the addition of confinement to improve deformability is generally less effective in heavily-reinforced and over-reinforced beam sections. From Fig. 7(b), it can be seen that the differential coefficient $\partial \theta_{p l} / \partial f_{r}$ decreases dramatically as the concrete strength $f_{c o}$ increases until it reaches a steady value at $f_{c o} \geq 90 \mathrm{MPa}$. This indicates that the increase in deformability of concrete beam per unit increase in confining pressure is always smaller at a higher concrete strength and therefore the addition of confinement to improve deformability is generally more difficult in HSC beam sections. In short, it is clear that maintaining the deformability of HSC beams is somewhat difficult and may require a substantial amount of confinement, if no upper limit is set on the degree of reinforcement or concrete strength.

\subsection{Effects of beam dimensions}

Since only a particular size of beam section is selected in the present parametric study for deformability analysis, it is essential to verify that the normalised rotation capacity of concrete beam is relatively insensitive to its cross-section dimensions. The effects were studied by comparing the normalised rotation capacity of beams obtained from three different cross-section dimensions (breadth $\times$ height): $200 \times 400 \mathrm{~mm}^{2}, 300 \times 600 \mathrm{~mm}^{2}$ and $500 \times 1000 \mathrm{~mm}^{2}$. The obtained normalised rotation capacities for these sections are shown in Fig. 8(a) for various concrete strengths and Fig. 8(b) for various degrees of reinforcement. It can be seen from these figures that the variation of normalised rotation capacity at various concrete strength and degrees of reinforcement is very small. Therefore, it can be said that the deformability of concrete beams is relatively insensitive to the cross-section dimensions compared with other factors such as concrete strength, degree of reinforcement and confining pressure. 


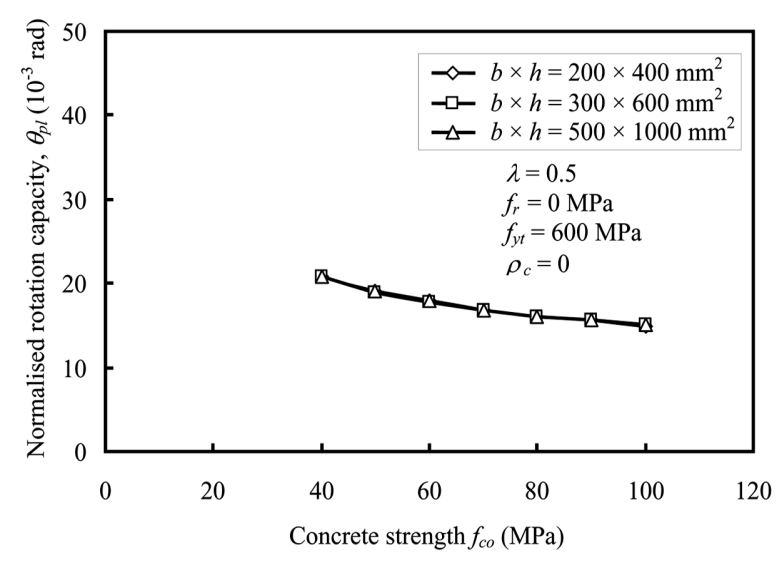

(a)

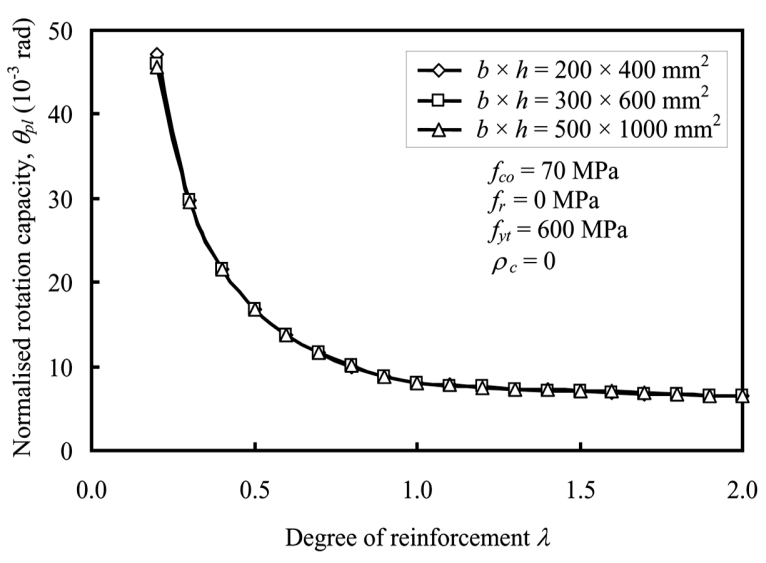

(b)

Fig. 8 Effects of beam dimensions on flexural deformability of beams: (a) $\theta_{p l}$ against $f_{c o}$, (b) $\theta_{p l}$ against $\lambda$

\section{Formula for direct evaluation of flexural deformability}

\subsection{Factors affecting the deformability}

The above parametric study revealed that the major factors affecting the flexural deformability of concrete beams are the concrete strength, degree of reinforcement and confining pressure. Hence, when evaluating the flexural deformability of concrete beams, all these factors need to be considered. From Fig. 3(a), it is apparent that the flexural deformability of over-reinforced concrete beams $(\lambda>1.0)$ remains relatively constant and is insensitive to the degree of reinforcement. Therefore the deformability evaluation of under- and over-reinforced beams should be dealt with separately.

\subsection{Formulas for deformability evaluation}

To enable a rapid evaluation of deformability of concrete beams without conducting lengthy nonlinear moment-curvature analysis, the evaluated normalised rotation capacity $\theta_{p l}$ obtained from the parametric study have been correlated to the studied parameters using regression analysis. For under-reinforced and balanced beam sections $(\lambda \leq 1.0)$, the following formula is developed based on Kwan et al. (2004)

$$
\begin{gathered}
\theta_{p l}=0.03 m\left(f_{c o}\right)^{-0.3}(\lambda)^{-1.0 n}\left(1+110\left(f_{c o}\right)^{-1.1}\left(\frac{f_{y c} \rho_{c}}{f_{y t} \rho_{t}}\right)^{3}\right)\left(\frac{f_{y t}}{460}\right)^{0.3} \\
m=1+4 f_{c o}^{0.4}\left(f_{r} / f_{c o}\right) \\
n=1+3 f_{c o}^{0.2}\left(f_{r} / f_{c o}\right)
\end{gathered}
$$

where $f_{c o}, f_{y c}, f_{y t}$ and $f_{r}$ are in MPa, $\lambda \leq 1.0$ and $400 \leq f_{y c}$ and $f_{y t} \leq 800 \mathrm{MPa}$. For over-reinforced beam sections $(\lambda>1.0)$, the following formula is obtained by replacing $\lambda=1.0$ in Eq. (5a) since the effect of $\lambda$ on deformability is now insignificant: 


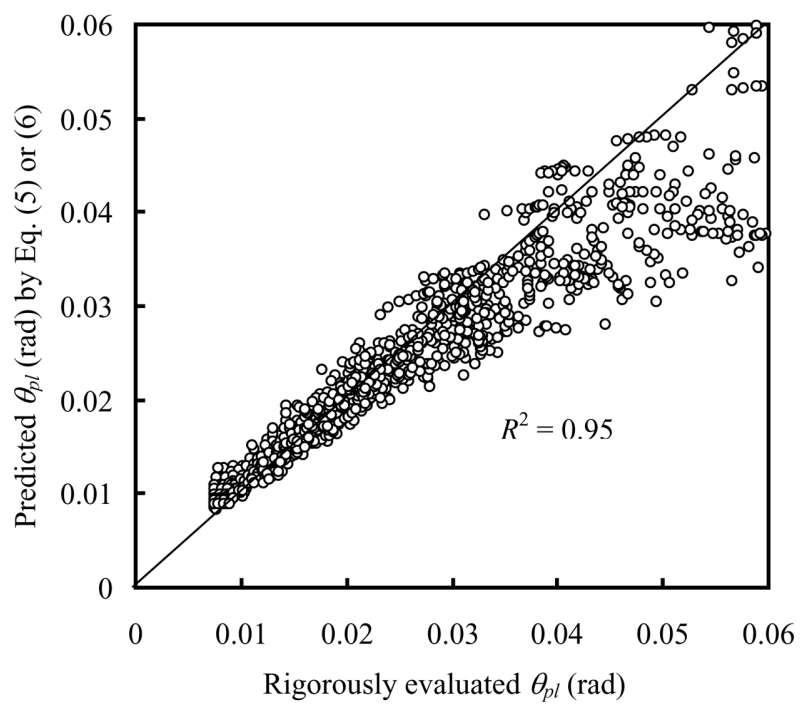

Fig. 9 Predicted flexural deformability plotted against vigorously evaluated values

$$
\theta_{p l}=0.03 m\left(f_{c o}\right)^{-0.3}\left(1+110\left(f_{c o}\right)^{-1.1}\left(\frac{f_{y c} \rho_{c}}{f_{y t} \rho_{t}}\right)^{3}\right)\left(\frac{f_{y t}}{460}\right)^{0.3}
$$

Furthermore, since over-reinforced beams usually contain tension steel much more than the compression steel, Eq. (6a) can be further simplified to Eq. (6b) by considering $\rho_{c} / \rho_{t} \approx 0$ in Eq. (6a)

$$
\theta_{p l}=0.03 m\left(f_{c o}\right)^{-0.3}\left(\frac{f_{y t}}{460}\right)^{0.3}=0.03 m\left(\frac{f_{y t} / 460}{f_{c o}}\right)^{0.3}
$$

The predicted normalised rotation capacity $\theta_{p l}$ obtained from Eqs. (5) and (6) are compared with the corresponding rigorously evaluated $\theta_{p l}$ by nonlinear moment-curvature analysis in Fig. 9. Statistical analysis shows that $80 \%$ of the evaluated $\theta_{p l}$ are within $\pm 10 \%$ error and $90 \%$ of the evaluated $\theta_{p l}$ are within $\pm 15 \%$ error. A fairly high coefficient of correlation $R^{2}=0.95$ is obtained. Hence, within the range of parameters covered in the present study, Eqs. (5) and (6) should be sufficiently accurate for predicting the deformability of concrete beams without performing the cumbersome nonlinear moment-curvature analysis. The practical application of the proposed formulas on concrete beam design is presented elsewhere (Ho and Zhou 2010).

\subsection{Comparison with experimental results of static beam tests}

To verify the validity of the above formulas, the flexural deformability predicted by Eq. (5) or Eq. (6) has been compared with the rotation capacities of concrete beams obtained experimentally for NSC beams (Nawy et al. 1968, Pecce and Fabbrocino 1999, Debernardi and Taliano 2002, Haskett et al. 2009) and HSC beams (Pecce and Fabbrocino 1999, Ko et al. 2001, Lopes and Bernardo 2003 ) by other researchers during static beam tests as well as those proposed by Eurocode 2 (ECS 2004). The comparisons of NSC and HSC beams are summarised in Tables 4 and 5 respectively. For comparison purpose, the value of $f_{c o}$ is taken as the value of $0.85 \eta f_{c}^{\prime}$, where $\eta$ is the ratio of the 
Table 4 Comparison with experimental results on rotation capacities of NSC beams

\begin{tabular}{|c|c|c|c|c|c|c|c|c|c|c|}
\hline Code & $\begin{array}{c}f_{c}^{\prime} \\
(\mathrm{MPa})\end{array}$ & $\begin{array}{c}f_{r} \\
(\mathrm{Mpa})\end{array}$ & $\begin{array}{c}f_{y t} \\
(\mathrm{Mpa})\end{array}$ & $\begin{array}{c}\rho_{t} \\
(\%)\end{array}$ & $\begin{array}{c}\rho_{c} \\
(\%)\end{array}$ & $\begin{array}{c}\theta_{p l} \text { by } \\
\begin{array}{c}\text { Eq. }(5) \\
\text { (rad) }\end{array} \\
{[1]}\end{array}$ & $\begin{array}{c}\begin{array}{c}\theta_{p l} \text { by } \\
\text { others } \\
(\mathrm{rad})\end{array} \\
{[2]}\end{array}$ & $\begin{array}{c}\theta_{p l} \text { by } \\
\text { EC2 } \\
(\mathrm{rad})\end{array}$ & $\frac{[1]}{[2]}$ & $\frac{[3]}{[2]}$ \\
\hline \multicolumn{11}{|c|}{ Nawy et al. (1968) } \\
\hline P9G1 & 33.6 & 0.00 & 328 & 1.73 & 0.71 & 0.0870 & 0.0650 & 0.0330 & 1.34 & 0.51 \\
\hline P11G3 & 35.1 & 0.50 & 328 & 1.73 & 0.71 & 0.1536 & 0.1110 & 0.0320 & 1.38 & 0.29 \\
\hline P3G4 & 37.5 & 1.30 & 452 & 1.73 & 0.71 & 0.1232 & 0.1340 & 0.0260 & 0.92 & 0.19 \\
\hline P4G5 & 39.1 & 1.30 & 452 & 1.73 & 0.71 & 0.1217 & 0.1360 & 0.0265 & 0.89 & 0.19 \\
\hline \multicolumn{11}{|c|}{ Pecce and Fabbocino (1999) } \\
\hline A & 41.3 & 0.98 & 471 & 2.60 & 0.05 & 0.0255 & 0.0220 & 0.0100 & 1.16 & 0.45 \\
\hline B & 41.3 & 0.94 & 454 & 1.10 & 0.05 & 0.0736 & 0.1220 & 0.0265 & 0.60 & 0.22 \\
\hline \multicolumn{11}{|c|}{ Debernardi and Taliano (2002) } \\
\hline T1A1 & 27.7 & 0.46 & 587 & 0.67 & 0.30 & 0.1433 & 0.1035 & 0.0310 & 1.38 & 0.30 \\
\hline T3A1 & 27.7 & 0.46 & 587 & 2.00 & 0.59 & 0.0270 & 0.0290 & 0.0080 & 0.93 & 0.28 \\
\hline T5A1 & 27.7 & 0.35 & 587 & 0.63 & 0.22 & 0.0978 & 0.1130 & 0.0300 & 0.87 & 0.27 \\
\hline T6A1 & 27.7 & 0.35 & 587 & 1.28 & 0.22 & 0.0311 & 0.0245 & 0.0160 & 1.27 & 0.65 \\
\hline \multicolumn{11}{|c|}{ Haskett et al. (2009) } \\
\hline A 1 & 38.2 & 0.67 & 315 & 1.47 & 0.0 & 0.0313 & 0.0360 & 0.0269 & 0.87 & 0.75 \\
\hline A2 & 42.3 & 0.32 & 318 & 1.47 & 0.0 & 0.0226 & 0.0205 & 0.0280 & 1.10 & 1.37 \\
\hline A3 & 41.0 & 0.31 & 336 & 1.47 & 0.0 & 0.0209 & 0.0168 & 0.0270 & 1.24 & 1.61 \\
\hline A4 & 42.9 & 1.29 & 315 & 2.95 & 0.0 & 0.0222 & 0.0305 & 0.0172 & 0.73 & 0.56 \\
\hline A5 & 39.6 & 0.59 & 314 & 2.95 & 0.0 & 0.0136 & 0.0207 & 0.0154 & 0.66 & 0.74 \\
\hline A6 & 41.1 & 0.31 & 328 & 2.95 & 0.0 & 0.0103 & 0.0118 & 0.0153 & 0.87 & 1.30 \\
\hline B1 & 43.0 & 0.65 & 329 & 1.47 & 0.0 & 0.0293 & 0.0277 & 0.0278 & 1.06 & 1.00 \\
\hline B2 & 41.8 & 0.31 & 322 & 1.47 & 0.0 & 0.0222 & 0.0152 & 0.0277 & 1.46 & 1.82 \\
\hline B3 & 42.9 & 1.29 & 321 & 2.95 & 0.0 & 0.0217 & 0.0218 & 0.0168 & 1.00 & 0.77 \\
\hline B4 & 42.9 & 0.64 & 323 & 2.95 & 0.0 & 0.0138 & 0.0120 & 0.0166 & 1.15 & 1.38 \\
\hline $\mathrm{C} 2$ & 26.0 & 0.39 & 329 & 1.47 & 0.0 & 0.0219 & 0.0258 & 0.0203 & 0.85 & 0.79 \\
\hline $\mathrm{C} 3$ & 25.6 & 0.32 & 330 & 1.47 & 0.0 & 0.0201 & 0.0187 & 0.0200 & 1.07 & 1.07 \\
\hline $\mathrm{C} 4$ & 25.9 & 1.23 & 325 & 2.95 & 0.0 & 0.0205 & 0.0297 & 0.0080 & 0.69 & 0.27 \\
\hline $\mathrm{C} 5$ & 23.4 & 0.64 & 328 & 2.95 & 0.0 & 0.0126 & 0.0130 & 0.0080 & 0.97 & 0.62 \\
\hline \multirow[t]{3}{*}{ C6 } & 27.4 & 0.34 & 319 & 2.95 & 0.0 & 0.0102 & 0.0125 & 0.0080 & 0.82 & 0.64 \\
\hline & & & & & & & & Average & 1.01 & 0.72 \\
\hline & & & & & & & \multicolumn{2}{|c|}{ Standard deviation } & 0.24 & 0.47 \\
\hline
\end{tabular}


Table 5 Comparison with experimental results on rotation capacities of HSC beams

\begin{tabular}{|c|c|c|c|c|c|c|c|c|c|c|}
\hline Code & $\begin{array}{c}f_{c}^{\prime} \\
(\mathrm{MPa})\end{array}$ & $\begin{array}{c}f_{r} \\
(\mathrm{Mpa})\end{array}$ & $\begin{array}{c}f_{y t} \\
(\mathrm{Mpa})\end{array}$ & $\begin{array}{c}\rho_{t} \\
(\%)\end{array}$ & $\begin{array}{c}\rho_{c} \\
(\%)\end{array}$ & $\begin{array}{c}\theta_{p l} \text { by } \\
\text { Eq. (5) } \\
\text { (rad) }\end{array}$ & $\begin{array}{c}\begin{array}{c}\theta_{p l} \text { by } \\
\text { others } \\
\text { (rad) }\end{array} \\
{[2]}\end{array}$ & $\begin{array}{c}\begin{array}{c}\theta_{p l} \text { by } \\
\mathrm{EC} 2 \\
(\mathrm{rad})\end{array} \\
{[3]}\end{array}$ & $\frac{[1]}{[2]}$ & $\frac{[3]}{[2]}$ \\
\hline \multicolumn{11}{|c|}{ Pecce and Fabbocino (1999) } \\
\hline $\mathrm{AH}$ & 93.8 & 0.98 & 471 & 2.60 & 0.05 & 0.0271 & 0.0220 & 0.0170 & 1.23 & 0.77 \\
\hline $\mathrm{CH}$ & 95.4 & 1.11 & 534 & 2.20 & 0.04 & 0.0300 & 0.0380 & 0.0170 & 0.79 & 0.45 \\
\hline \multicolumn{11}{|c|}{ Ko et al. (2001) } \\
\hline $6-65-1$ & 66.6 & 2.26 & 415 & 3.59 & 0.79 & 0.0547 & 0.0472 & 0.0150 & 1.16 & 0.32 \\
\hline $6-75-1$ & 66.6 & 2.33 & 427 & 4.27 & 0.77 & 0.0399 & 0.0412 & 0.0100 & 0.97 & 0.24 \\
\hline $8-50-1$ & 82.1 & 2.42 & 443 & 3.35 & 0.80 & 0.0580 & 0.0482 & 0.0160 & 1.20 & 0.33 \\
\hline $8-65-1$ & 82.1 & 2.33 & 427 & 4.27 & 0.77 & 0.0398 & 0.0450 & 0.0100 & 0.88 & 0.22 \\
\hline $8-75-1$ & 82.1 & 2.15 & 394 & 4.97 & 0.79 & 0.0338 & 0.0484 & 0.0080 & 0.70 & 0.17 \\
\hline $7-62^{00}-1$ & 70.8 & 1.91 & 408 & 3.16 & 0.00 & 0.0403 & 0.0530 & 0.0135 & 0.76 & 0.25 \\
\hline $7-62^{15}-1$ & 70.8 & 1.91 & 408 & 3.16 & 0.79 & 0.0587 & 0.0510 & 0.0160 & 1.15 & 0.31 \\
\hline \multicolumn{11}{|c|}{ Lopes and Bernardo (2003) } \\
\hline $\mathrm{A}(64.9-2.04)$ & 64.9 & 0.59 & 555 & 2.04 & 0.20 & 0.0248 & 0.0200 & 0.0210 & 1.24 & 1.05 \\
\hline $\mathrm{A}(63.2-2.86)$ & 63.2 & 0.62 & 575 & 2.86 & 0.20 & 0.0161 & 0.0180 & 0.0110 & 0.89 & 0.61 \\
\hline $\mathrm{A}(65.1-2.86)$ & 65.1 & 0.62 & 575 & 2.86 & 0.20 & 0.0161 & 0.0150 & 0.0110 & 1.07 & 0.73 \\
\hline $\mathrm{B}(82.9-2.11)$ & 82.9 & 0.59 & 555 & 2.11 & 0.20 & 0.0243 & 0.0210 & 0.0180 & 1.16 & 0.86 \\
\hline $\mathrm{B}(83.9-2.16)$ & 83.9 & 0.59 & 555 & 2.16 & 0.20 & 0.0237 & 0.0200 & 0.0180 & 1.19 & 0.90 \\
\hline $\mathrm{B}(83.6-2.69)$ & 83.6 & 0.62 & 575 & 2.69 & 0.20 & 0.0178 & 0.0210 & 0.0150 & 0.85 & 0.71 \\
\hline \multirow[t]{3}{*}{$\mathrm{B}(83.4-2.70)$} & 83.4 & 0.62 & 575 & 2.70 & 0.20 & 0.0177 & 0.0200 & 0.0150 & 0.89 & 0.75 \\
\hline & & & & & & & & Average & 1.01 & 0.54 \\
\hline & & & & & & & \multicolumn{2}{|c|}{ Standard deviation } & 0.18 & 0.28 \\
\hline
\end{tabular}

average concrete stress of the equivalent rectangular stress block to the cylinder strength $f_{c}{ }^{\prime}$ as stipulated in Eurocode 2. The confining pressure provided by the confinement is evaluated using the confinement effectiveness factor proposed by Mander et al. (1988). The length of plastic hinge from the point of maximum moment in the beam is taken as the lower bound value of $0.4 d$ obtained by Mendis (2001), where $d$ is the effective depth.

From Tables 4 and 5 , it is evident that:

(1) The rotation capacities of concrete beams evaluated using Eq. (5) or Eq. (6) agree reasonably closely with the measured rotation capacities for both NSC and HSC beams. The differences between the rotation capacities obtained from Eq. (5) or Eq. (6) and the measured rotation capacities are mostly within $30 \%$. The average ratio (and standard deviation) of the proposed to the measured rotation capacities is $1.01(0.24)$ for NSC and $1.01(0.18)$ for HSC beams.

(2) The rotation capacities of concrete beams calculated in accordance with Eurocode 2 are actually too conservative. The maximum difference between the rotation capacities obtained 
from Eurocode 2 and the measured rotation capacities can be up to $80 \%$ for both NSC and HSC beams. The average ratio (and standard deviation) of the theoretical to measured rotation capacities is $0.72(0.47)$ for NSC beams but reduces to $0.54(0.28)$ for HSC beams. This indicates that the prediction of rotation capacities by Eurocode 2 is more conservative for HSC beams than NSC beams.

(3) Therefore, Eqs. (5) and (6) are more accurate in predicting the rotation capacities of both NSC and HSC beams than Eurocode 2 within the range of concrete strength, steel yield strength and confining pressure covered in this study.

\section{Conclusions}

The flexural deformability of NSC and HSC beams expressed in terms of normalised rotation capacity with NSS and/or HSS has been investigated by a comprehensive parametric study based on nonlinear moment-curvature analysis taking into account the stress-path dependence of reinforcement. From the study, it was evident that the most critical factors that affect the deformability of concrete beams are the degree of reinforcement $\lambda$, concrete strength and confining pressure. In general, for under-reinforced and balanced beam sections $(\lambda \leq 1.0)$, the deformability decreases as $\lambda$ increases, while for over-reinforced beam sections $(\lambda>1.0)$, the deformability remains relatively constant with $\lambda$. On the other hand, the effects of concrete strength on deformability of concrete beams are dependent on $\lambda$ and tension steel ratio $\rho_{t}$. At a fixed $\lambda$, the deformability decreases as the concrete strength increases; whereas at a fixed tension steel ratio, the deformability increases as the concrete strength increases albeit that HSC is more brittle per se. Lastly, the deformability of concrete beams always increases as the confining pressure increases. Nonetheless, the effectiveness of adding confinement in deformability improvement, which was studied in this paper by the differential coefficient $\partial \theta_{p l} \partial f_{r}$, decreases as the degree of reinforcement or concrete strength increases.

The effects of using HSS on deformability of concrete beams was studied by the factor $\lambda$. With the adoption of HSS as tension steel, the deformability of beam decreases at a fixed tension steel ratio. Nevertheless, for the same flexural strength requirement, the use of HSS as tension steel will allow a smaller steel area. Hence, the deformability of concrete beam may or may not be significantly affected. On the contrary, the adoption of HSS as compression steel would always increase the deformability of concrete beams.

Two empirical formulas were developed for rapid evaluation of deformability of NSC and HSC beams without performing the nonlinear moment-curvature analysis. These formulas have been compared with the measured rotation capacities of NSC and HSC beams obtained experimentally by other researchers, in which reasonably good agreement was obtained. It has also been shown that the formulas can predict rotation capacities of NSC and HSC beams more accurately than Eurocode 2 , which prediction is too conservative.

\section{Acknowledgements}

Support from Seed Funding Programme for Basic Research (Project Code: 200802159007) provided by The University of Hong Kong is gratefully acknowledged. 


\section{References}

Altin, S., Kuran, F., Anil, Ö. and Emin Kara M. (2008), "Rehabilitation of heavily earthquake damaged masonry building using steel straps", Struct. Eng. Mech., 30(6), 651-664.

Attard, M.M. and Setunge, S. (1996), "The stress strain relationship of confined and unconfined concrete", $A C I$ Mater. J., 93(5), 432-442.

Au, F.T.K., Chan, K.H.E., Kwan, A.K.H. and Du, J.S. (2009), "Flexural ductility of prestressed concrete beams with unbonded tendons", Comput. Concrete, 6(6), 451-472.

Bai, Z.Z. and Au, F.T.K. (2009) "Effects of strain hardening of reinforcement on flexural strength and ductility of reinforced concrete columns", Struct. Des. Tall Spec., doi:10.1002/tal.554

Bai, Z.Z., Au, F.T.K. and Kwan, A.K.H. (2007), "Complete nonlinear response of reinforced concrete beams under cyclic loading", Struct. Des. Tall Spec., 16, 107-130.

Belarbi, A., Prakash, S. and You, Y.M. (2009), "Effect of spiral reinforcement on flexural-shear torsional seismic behavior of reinforced concrete circular bridge column", Struct. Eng. Mech., 33(2), 137-158.

Bechtoula, H., Kono, S. and Watanabe, F. (2009), "Seismic performance of high strength reinforced concrete columns", Struct. Eng. Mech., 31(6), 697-716.

Bindhu, K.R., Jaya, K.P. and Manicka Selvam, V.K. (2008), "Seismic resistance of exterior beam-column joints with non-conventional confinement reinforcement detailing", Struct. Eng. Mech., 30(6), 733-761.

Carrasquillo, R.L., Nilson, A.H. and Slate, F.O. (1981), "Properties of high strength concrete subjected to shortterm loads", ACI J., Proceedings 78(3), 171-178.

Cho, C.G., Ha, G.J. and Kim, Y.Y. (2008), "Nonlinear model of reinforced concrete frames retrofitted by in-filled HPFRCC walls", Struct. Eng. Mech., 30(2), 211-223.

Debernardi, P.G. and Taliano, M. (2002), "On evaluation of rotation capacity of reinforced concrete beams", $A C I$ Struct. J., 99(3), 360-368.

Englekirk, R.E. (2008), “A call for change in seismic design procedures”, Struct. Des. Tall Spec., 17, 10051013.

ECS, European Committee for Standardization (2004), /Eurocode 2:/ Design of concrete structures: Part 1-1: General rules and rules for buildings, UK, 225pp.

Feng, R. and Young, B. (2009) "Behaviour of Concrete-filled Stainless Steel Tubular X-joints subjected to Compression", Thin Wall. Struct., 47(4), 365-374.

Goel, R.K. (2010), "Approximate seismic displacement capacity of piles in marine oil terminals", Earthq. Struct., 1(1), 129-146.

Hashemi, S.H., Maghsoudi, A.A. and Rahgozar, R. (2008), "Flexural ductility of reinforced HSC beams strengthened CFRP sheets", Struct. Eng. Mech., 30(4), 403-426.

Haskett, M., Oehlers, D.J., Mohamed, Ali, M.S. and Wu, C. (2009), "Rigid body moment-rotation mechanism for reinforced concrete beam hinges", Eng. Struct., 31, 1032-1041.

Hawileh, R.A., Malhas, F.A. and ,Rahman A. (2009), "Comparison between ACI 318-05 and Eurocode 2 (EC294) in flexural concrete design", Struct. Eng. Mech., 32(6), 705-724.

Ho, J.C.M., Au, F.T.K. and Kwan, A.K.H. (2005), "Effects of strain hardening of steel reinforcement on flexural strength and ductility of concrete beams", Struct. Eng. Mech., 19(2), 185-198.

Ho, J.C.M., Kwan, A.K.H. and Pam, H.J. (2003), "Theoretical analysis of post-peak flexural behaviour of normal- and high-strength concrete beams", Struct. Des. Tall Spec., 12, 109-125.

Ho, J.C.M., Kwan, A.K.H. and Pam, H.J. (2004), "Minimum flexural ductility design of high-strength concrete beams", Mag. Concrete Res., 56(1), 13-22.

Ho, J.C.M., Lam, J.Y.K. and Kwan, A.K.H. (2010a), "Effectiveness of adding confinement for ductility improvement of high-strength concrete columns", Eng. Struct., 32, 714-725.

Ho, J.C.M., Lam, J.Y.K. and Kwan, A.K.H. (2010b), "Flexural ductility and deformability of concrete beams incorporating high-performance materials", Struct. Des. Tall Spec., doi:/10.1002/tal.579

Ho, J.C.M. and Pam, H.J. (2003), "Inelastic design of low-axially loaded high-strength reinforced concrete columns", Eng. Struct., 25(8), 1083-1096.

Ho, J.C.M. and Zhou, K.J.H. (2010), "Concurrent flexural strength and deformability design of high-performance concrete beams", Struct. Eng. Mech., (submitted). 
Ko, M.Y., Kim, S.W. and Kim, J.K. (2001), "Experimental study on the plastic rotation capacity of reinforced high strength concrete beams", Mater. Struct., 34, 302-311.

Kwak, H.G. and Kim, S.P. (2010), "Simplified monotonic moment-curvature relation considering fixed-end rotation and axial force", Eng. Struct., 32, 69-79.

Kwan, A.K.H., Au, F.T.K. and Chau, S.L. (2004), "Effects of confinement on flexural strength and ductility design of HS concrete beams", Struct. Eng., 84(23-24), 38-44.

Lam, S.S.E., Wu, B., Liu, Z.Q. and Wong, Y.L. (2008), "Experimental study on seismic performance of coupling beams not designed for ductility", Struct. Eng.Mech., 28(3), 317-333.

Lam, J.Y.K., Ho, J.C.M. and Kwan, A.K.H. (2009), "Flexural ductility of high-strength concrete columns with minimal confinement", Mater. Struct., 42(7), 909-921.

Lee, H.K., Ha, S.K. and Afzal, M. (2008), "Finite element analysis of shear-deficient RC beams strengthened with CFRP strips/sheets", Struct. Eng. Mech., 30(2), 247-261.

Lopes, S.M.R. and Bernardo, L.F.A. (2003), "Plastic rotation capacity of high-strength concrete beams", Mater. Struct., 36, 22-31.

Lu, Y. (2009), "Modelling of concrete structures subjected to shock and blast loading: an overview and some recent studies", Struct. Eng. Mech., 32(2), 235-249.

Mahini, S.S. and Ronagh, H.R. (2009), "Numerical modeling of FRP strengthened RC beam-column joints", Struct. Eng. Mech., 32(5), 649-665.

Mander, J.B., Priestley, M.J.N. and Park, R. (1988), "Theoretical stress-strain model for confined concrete", $J$. Struct. Eng. - ASCE, 114(8), 1804-1825.

Mendis, P. (2001), "Plastic hinge lengths of normal and high-strength concrete in flexure", Adv. Struct. Eng., 4(4), 189-195.

Nam, J.W., Kim, H.J., Yi, N.H., Kim, I.S., Kim, J.J.H. and Choi, H.J. (2009), "Blast analysis of concrete arch structures for FRP retrofitting design", Comput. Concrete, 6(4), 305-318.

Nawy, E.G., Danesi, R.F. and Grosko, J.J. (1968), "Rectangular spiral binders effect on plastic hinge rotation capacity in reinforced concrete beams", ACI J., 65(12), 1001-1010.

Pam, H.J. and Ho, J.C.M. (2001), "Flexural strength enhancement of confined reinforced concrete columns", Proc. Inst. Civil Eng. Struct. Build., 146(4), 363-370.

Pam, H.J. and Ho, J.C.M. (2009), "Length of critical region for confinement steel in limited ductility highstrength reinforced concrete columns", Eng. Struct., 31, 2896-2908.

Pam, H.J. and Ho, J.C.M. (2010), "Effects of steel lap splice locations on strength and ductility of reinforced concrete columns", Adv. Struct. Eng., 13(1), 1-16.

Pam, H.J., Kwan, A.K.H. and Ho, J.C.M. (2001), "Post-peak behavior and flexural ductility of doubly reinforced normal- and high-strength concrete beams", Struct. Eng. Mech., 12(5), 459-474.

Park, J.W. and Kim, S.E. (2008), "Nonlinear inelastic analysis of steel-concrete composite beam-columns using stability functions", Struct. Eng. Mech., 30(6), 763-785.

Park, H.S., Seo, J.H. and Kwon, Y.H. (2008), "Development of drift design model for high-rise buildings subjected to lateral and vertical loads", Struct. Des. Tall Spec., 17, 273-293.

Pecce, M. and Fabbrocino, G. (1999), "Plastic rotation capacity of beams in normal and high-performance concrete", ACI Struct. J., 96(2), 290-296.

Ramadoss, P. and Nagamani, K. (2009), "Behavior of high-strength fiber reinforced concrete plates under inplane and transverse loads", Struct. Eng. Mech., 31(4), 371-382.

Restrepo, J.I., Seible, F., Stephan, B. and Schoettler, M.J. (2006), "Seismic testing of bridge columns incorporating high-performance materials", ACI Struct. J., 103(4), 496-504.

Sadjadi, R. and Kianoush, M.R. (2010), "Application of fiber element in the assessment of the cyclic loading behavior of RC columns", Struct. Eng. Mech., 34(3), 301-317.

Su, R.K.L., Lam, W.Y. and Pam, H.J. (2009) "Experimental study of plate-reinforced composite deep coupling beams", Struct. Des. Tall Spec., 18, 235-257.

Teran-Gilmore, A., Sanzhez-Badillo, A. and Espinosa-Johnson, M. (2010), "Performance-based seismic design of reinforced concrete ductile buildings subjected to large energy demands", Earthq. Struct., 1(1), 129-146.

Watson, S. and Park, R. (1994), "Simulated seismic load tests on reinforced concrete columns", J. Struct. Eng. $A S C E$, 120(6), 1825-1849. 
Weerheijm, J., Mediavilla, J. and van Doormaal, J.C.A.M. (2009), "Explosive loading of multi storey RC buildings: Dynamic response and progressive collapse", Struct. Eng. Mech., 32(2), 193-212.

Wu, Y.F. (2008), "Ductility demand of compression yielding fiber-reinforced polymer-reinforced concrete beams", ACI Struct. J., 105(1), 104-110.

Wu, Y.F., Oehlers, D.J. and Griffith, M.C. (2004), "Rational definition of the flexural deformation capacity of RC column sections", Eng. Struct., 26, 641-650.

Zhu, Y. and Su, R.K.L. (2010), "Seismic behavior of strengthened reinforced concrete coupling beams by bolted steel plates, Part 2: Evaluation of theoretical strength", Struct. Eng. Mech., 34(5), 563-580.

$I T$

\section{Notations}

$A_{s b} \quad$ Balanced steel area

$A_{s c} \quad$ Area of compression reinforcement

$A_{s t} \quad$ Area of tension reinforcement

$b \quad$ Breadth of beam section

$d \quad$ Effective depth of beam section

$d^{\prime} \quad$ Distance from extreme compressive fibre to centroid of compression steel

$d_{n} \quad$ Depth to neutral axis

$E_{s} \quad$ Elastic modulus of steel reinforcement

$f_{c}^{\prime} \quad$ Concrete compressive cylinder strength

$f_{c o} \quad$ Peak stress on stress-strain curve of unconfined concrete

$f_{y} \quad$ Yield strength of steel reinforcement

$f_{y c} \quad$ Yield strength of compression reinforcement

$f_{y t} \quad$ Yield strength of tension reinforcement

$f_{r} \quad$ Confining pressure

$h \quad$ Total depth of the beam section

$l_{p} \quad$ Plastic hinge length

$M_{p} \quad$ Peak moment

$\partial \theta_{p l} / \partial f_{r}$ Rate of change of normalised rotation capacity with respect to confining pressure

$\varepsilon_{p s} \quad$ Residual plastic strain in steel reinforcement

$\varepsilon_{s} \quad$ Strain in steel reinforcement

$\varepsilon_{y} \quad$ Yield strain of steel reinforcement

$\eta \quad$ Ratio of average concrete stress to cylinder strength

$\theta_{p l} \quad$ Normalised rotation capacity of beam

$\lambda \quad$ Degree of reinforcement (Eq. 4)

$\phi_{u} \quad$ Ultimate curvature

$\rho_{b} \quad$ Balanced steel ratio $\left(=A_{s b} / b d\right)$

$\rho_{b o} \quad$ Balanced steel ratio for beam section with no compression reinforcement

$\rho_{c} \quad$ Compression reinforcement ratio $\left(=A_{s c} b d\right)$

$\rho_{t} \quad$ Tension reinforcement ratio $\left(=A_{s t} / b d\right)$

$\sigma_{s} \quad$ Stress in steel reinforcement 